\title{
Effects of selective antagonism or depletion of the cholinergic system on visual discrimination performance in rats
}

\author{
W.H.I.M. Drinkenburg, ${ }^{1}$ H.N.P.M. Sondag, ${ }^{1}$ C.J.H. Coenders, ${ }^{1}$ J.S. Andrews ${ }^{2}$ and \\ J.M.H. Vossen ${ }^{1}$ \\ ${ }^{1}$ Department of Comparative and Physiological Psychology, University of Nijmegen, The \\ Netherlands; and ${ }^{2}$ Scientific Development Group, Organon International B.V. The Netherlands
}

Correspondence to: W.H.I.M. Drinkenburg, Nijmegen Institute of Cognition and Information, Department of Comparative and Physiological Psychology, University of Nijmegen, P.O. Box 9104,6500 HE Nijmegen. The Netherlands, E-mail; DRINKENBURG@NICI.KUN.NL

\begin{abstract}
A two-lever simultaneous visual discrimination task was used to study the effects on performance in Long-Evans rats of the muscarinic antagonists scopolamine $\left(0.0125,0.05,0.2\right.$ and $0.8 \mathrm{mg} / \mathrm{kg} \mathrm{s.c.)}$, the $M_{1}$ antagonist pirenzepine, the $M_{2}$ antagonist AF-DX 116, the $M_{3}$ antagonist UH-AH 37 (each 3.2, 10,32 $\mu \mathrm{g} / \mathrm{rat}$, i.c.v.) and the cholinergic depleting agent, hemicholinium-3 $(0.04,0.2,1.0$ and $5.0 \mu \mathrm{g} / \mathrm{rat}$ i.c.v.). Scopolamine dose-dependently decreased accuracy, increased the number of trials on which the rats failed to respond, and significantly lengthened latency to respond. Only the highest doses of hemicholinium-3, pirenzepine and AF-DX 116 reduced accuracy and increased errors of omission as well as response latency. UH-AH 37 reduced overall task performance at 10 and $32 \mu \mathrm{g}$, suggesting that antagonism of both $\mathbf{M}_{3}$ and other muscarinic receptors (including $M_{1}$ ) had a greater effect on performance than selective antagonism of the $M_{1}$ or $\mathbf{M}_{2}$ receptors. These data indicate that the disruptive effects of cholinergic antagonism on attentionally demanding tasks are strengthened by activity at multiple subtypes of the receptor.
\end{abstract}

Keywords: AF-DX 116 - Hemicholinium-3 - Learning - Memory - Muscarinic Receptors - Pirenzepine - Rat - Scopolamine - UH-AH 37 - Visual discrimination

\section{INTRODUCTION}

Age-related memory deficits, especially those found in Alzheimer's disease, have been attributed to loss of cholinergic function (Davies and Maloney, 1976; Coyle et al., 1983; Perry, 1986). Accordingly, the effects on learning and memory of substances which induce cholinergic hypofunction have been extensively investigated both in humans and animals (for reviews see Kopelman (1986), Hagan and Morris (1988)). The muscarinic receptor antagonist scopolamine has been widely used to induce amnestic effects in many species from rat to human (Hagan and Morris, 1988; Rupniak et al, 1990; Rusted et al., 1991). However, at certain doses of scopolamine, discriminability rather than memory is disturbed (Warburton and Brown, 1971; Ksir and Slifer, 1982; Kirk et al. 1988). Indeed, a broad range of non-specific effects on for example vigilance or attention, have been proposed as possible confounding factors for the putative direct effects on memory (Andrews et al., 1992; Dunnett et al., 1991; Rupniak et al., 1991).
At least five different subtypes of muscarinic cholinergic receptors can be identified within the central nervous system (Levey, 1993). The $M_{1}, M_{2}$ and $M_{3}$ receptors have received the most attention from pharmacologists, and consequently little is known about $\mathrm{M}_{4}$ and $\mathrm{M}_{5}$ receptors. The postsynaptic $M_{1}$ receptors are primarily located in the cerebral cortex and hippocampus (Mash et al., 1985; Araujo et al., 1988; Levey, 1993), whereas $M_{2}$ receptors, representing a class of autoreceptors, can be found in the cerebral cortex, various midbrain regions and brainstem nuclei (Messer et al., 1989; Levey, 1993). Lastly, the $\mathrm{M}_{3}$ receptors are located in the hippocampus as well as in other structures, but are less common in the central nervous system (CNS) than either the $M_{1}$ or $M_{2}$ receptors. Research into cholinergic based treatments for Alzheimer's disease has concentrated on the $M_{1}$ receptor, because this subtype appears to be preserved during the progression of the disease (Mash et al., 1985; Araujo et al., 1988). However, the exact role for the 
muscarinic subtypes in cognitive performance is still largely unclear.

Studies on the effects of specific muscarinic antagonists on cognitive performance are rare and studies on discriminability even rarer Most studies have been confined to the effects of the intracerebroventricular (i.c.v.) administration of the $M_{1}$ antagonist pirenzepine in spatial learning tasks (Hagan et al, 1987; Hunter and Roberts, 1988; Messer et al., 1990; Sala et al., 1991). Andrews et al. (1994) recently studied the effects of pirenzepine, AFDX 116 and UH-AH 37 after i.c.v. administration in a delayed matching to position (DMTP) task and found clear differences in the effects of these selective ligands. The $M_{1}$ receptor antagonist pirenzepine disrupted accuracy in a delay-, but not dose-related manner. After injection of pirenzepine into the hippocampus, Messer et al. (1990) also found a decrease in performance on a representational memory (non-matching-to-sample, T-maze) task. Less agreement exists about the consequences of antagonising the $\mathrm{M}_{2}$ receptor. Andrews et al. (1994) found no disruptions after central injection of the muscarinic $\mathrm{M}_{2}$ antagonist AF-DX 116. However, other studies reported a decrease in representational memory performance after hippocampal injection of AF-DX 116 (Messer et al, 1990). To date, only one study used the $M_{3}$ antagonist UH-AH 37 : in a delayed matching to position task UH-AH 37 was found to disrupt performance severely even in the zero delay condition (Andrews et al, 1994).

An alternative method of inducing cholinergic hypofunction is to deplete the cholinergic neurons of acetylcholine. To this end, i.c.v. injections of hemicholinium-3 (HC3), a high-affinity choline uptake blocker (Russell and Macri, 1978), have been used to induce a reversible cholinergic depletion. Although at high dosages behavioural disruptions have been reported (Freeman et al, 1975; Jenden et al, 1977), low doses of HC3 can induce cognitive deficits without accompanying motor disturbances (Ridley et al., 1984, 1987; Hagan et al, 1989; Muir et al., 1992; Andrews et al., 1994).

Given the knowledge that a generalised cholinergic blockade results in many non-specific, and probably non-cognitive, disruptive effects on behaviour, it is important to determine the effects on performance of cholinergic depletion as well as of antagonising cholinergic receptors. Therefore, the present experiment investigated the contribution of the muscarinic cholinergic system to task performance, by general and selective antagonism as well as by cholinergic depletion. The compounds used were chosen because their effects in a DMTP task are known and provide a reference for effects on delay-dependent and delay-independent performance. An operant two-lever visual discrimination task was chosen, as a similar task has proven useful in elucidating the effects of psychoactive drugs and lesions on performance (Andrews and Sahgal, 1984; Andrews and Holtzman, 1988; Evenden et al., 1989). These experiments help to establish whether blockade of a particular muscarinic subtype can disrupt visual discrimination in a similar manner to that repeatedly observed after general muscarinic blockade (e.g. Andrews et al, 1992), cholinergic lesions (e.g. Dunnett et al., 1991) or cholinergic depletion (e.g. Muir et al, 1992)

\section{MATERIALS AND METHODS}

\section{Subjects and surgery}

Subjects were male Long-Evans rats (supplied by HARLAN, Zeist), weighing approximately $275 \mathrm{~g}$ at the beginning of the experiment. Rats were individually housed in standard Makrolon cages and maintained on a $12: 12 \mathrm{~h}$ light : dark cycle, with lights on at $08.00 \mathrm{~h}$. A restricted feeding schedule (down to $90 \%$ of free-feeding weight) was introduced three days before training, but access to tap water was free at all times. After training the animals to criterion (see below) animals were allowed to free-feed for three days before surgery. Each rat was implanted under anaesthesia (Nembutal, $60 \mathrm{mg} / \mathrm{kg}$ i.p.) with a stainless steel guide cannula (Organon B. V., The Netherlands), aimed at the right lateral ventricle: coordinates from Bregma, $\quad A P=-0.8 \mathrm{~mm}, \quad$ Lat $=-1.5 \mathrm{~mm}$, HV $=3.0 \mathrm{~mm}$ (Paxinos and Watson, 1982). I.c.v. injections of dye histologically verified correct cannula positioning post mortem. Food deprivation was reinstated one week after surgery.

\section{Apparatus}

Eight operant chambers (L $27 \times W 25 \times H 24 \mathrm{~cm}$ ), equipped with two retractable levers, a centrally placed food tray and pellet dispenser (delivering $45 \mathrm{mg}$ pellets), red house light, and two cue light displays above the levers, were connected to Skinner Box Controllers and controlled by an Apple Macintosh SE 30 . Boxes, controllers and software were developed by the Electronic and Computer Engineering Department and the Mechanical Engineering Department of the Psychological Laboratory, University of Nijmegen. The cue light consisted of 64 green LEDs (PD 1167, Siemens), together forming a $25.4 \mathrm{~mm}$ square light.

\section{Visual discrimination learning}

Rats were initially trained to press the levers on an FR1 schedule of food reinforcement using an autoshaping schedule. Subsequently, both levers were permanently available in the chamber; when a cue light was presented, 
the rat was required to press the lever directly under the stimulus in order to obtain a food pellet and progress to the next trial. As soon as this task had been adequately mastered, training on the discrimination proper started. In the discrimination task, each trial began with the presentation of a light over one of the two levers, while at the same time both levers were inserted into the chamber. Upon pressing the correct lever, both levers were withdrawn, the cue light was switched off, the tray light was illuminated and a food pellet delivered. The next trial followed after a variable interval of $5 \mathrm{~s}$ mean duration (range $3.5-6.5 \mathrm{~s}$ ). If the rat failed to respond within $5 \mathrm{~s}$ or responded on the incorrect lever, the cue light was extinguished, the levers were withdrawn and no food pellet was delivered. In these cases the next trial began after a variable time-out interval of mean $10 \mathrm{~s}$ duration $(7.5-$ $12.5 \mathrm{~s}$ ). Each session consisted of 100 trials, in which the stimulus (left or right) occurred 50 times in a random order, the order of presentation of the stimuli was given in a different random pattern each day. Each animal received one session a day, five days a week. Over a period of four weeks the cue light duration was reduced in a step-wise manner from $5.0 \mathrm{~s}$ to $0.3 \mathrm{~s}$ to prevent ceiling effects in accuracy scores; if the rat responded correctly on at least $70 \%$ of all responses in one session, the stimulus duration was halved for the next session. The animals reached criterion when they completed three successive sessions using the final parameters with a minimum of $75 \%$ correct responses. Animals were then implanted with a cannula during a two-week period of surgery and recovery, thereafter, all animals were retrained to the pre-operation criterion. Parameters used for the final training session were also used for the drug testing session.

\section{Drug testing}

Separate groups of rats were used to study each dose of each drug in one-session studies. Rats were randomised prior to testing and the overall accuracy of the different groups evaluated; for each experiment the baseline performance of each group was equivalent on the training day immediately before testing. At least one week of drug-free training was allowed before further injection of compounds. Scopolamine (placebo, $0.0125,0.05,0.2$ and $0.8 \mathrm{mg} / \mathrm{kg}$, injection volume $1 \mathrm{ml} / \mathrm{kg} ; n=8 /$ group) was injected s.c. (neck) $30 \mathrm{~min}$ prior to test. HC3 (placebo, $0.04,0.02,1.0$ and $5.0 \mu \mathrm{g} / \mathrm{rat}$ in $5 \mu \mathrm{l}$ of merlys vehicle: $n=8$ (group) was infused into the ventricle over $30 \mathrm{~s}$, 60 min prior to test, using a CMA micropump. The same method was used to inject rats i.c.v. with pirenzepine and the structural analogues AF-DX 116 or UH-AH 37 (doses $0.0,3.2,10$ and $32 \mu \mathrm{g}$, in $5 \mu$ l merlys over $30 \mathrm{~s} ; n=10$ group) immediately before testing.

\section{Data analysis}

Accuracy as measured by percentage correct responding (calculated as the number of trials correct/number of trials on which a response occurred $\times 100$ ), errors of omission (missed trials), and response latency were analysed using a one-factor independent groups analysis of variance, followed, when significance was achieved, by Scheffe F post hoc testing. Rats which responded on fewer than ten trials were excluded from the analysis in order to prevent an extreme bias in the calculation of the errors of commission.

\section{RESULTS}

\section{Pirenzepine}

A significant drug effect was found for the percentage correct responses $[F(3,36)=4.56, p<0.01]$, for latency to respond $[F(3,36)=11.23, p<0.01]$, and for missed trials $[\mathrm{F}(3,36)=6.60, p<0.01]$. Post hoc testing revealed a decrease in percentage correct and an increase in response latency and missed trials only at the highest dose (Fig. 1, top panel).

\section{AF-DX 116}

Five rats injected with the highest dose $(32 \mu \mathrm{g})$ were discarded because they responded on fewer than ten trials. A significant drug effect was found for all parameters: the percentage correct responses $[F(3,31)=6.26$, $p<0.01]$, latency to respond $[\mathrm{F}(3,31)=4.67, p<0.01]$ and missed trials $[\mathrm{F}(3,31)=4.59, p<0.01]$. Post hoc testing revealed that only the highest dose decreased accuracy, and increased response latencies and failures to respond (Fig. 1, middle panel).

\section{UH-AH 37}

Five rats, which received the highest dose $(32 \mu \mathrm{g})$, and one rat injected with $10 \mu \mathrm{g}$ were discarded for failing to respond on the minimally required number of trials. A significant drug effect was found for percentage correct responses $[\mathrm{F}(3,30)=6.49, \quad p<0.01]$, missed trials $[F(3,30)=7.54, p<0.01]$ and latency to respond $[F(3,30)=8.80, p<0.01]$. Post hoc testing revealed a decrease in accuracy and an increase in response latencies at 10 and $32 \mu \mathrm{g}$ UH-AH 37 . The highest dose also increased the number of missed trials (Fig, 1, bottom panel).

\section{Scopolamine}

Scopolamine dose-dependently decreased accuracy $[\mathrm{F}(4,34)=14.4, p<0.01]$, and increased the number of missed trials $[F(4,34)=34.5, p<0.01]$ and response 


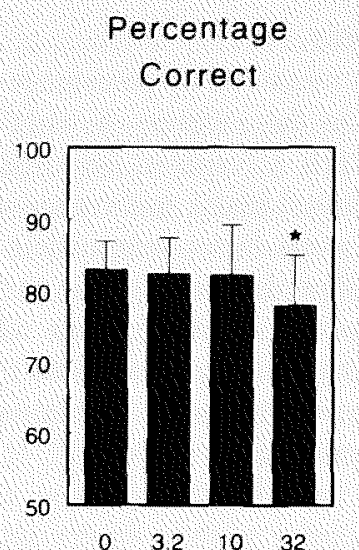

Missed

Trials

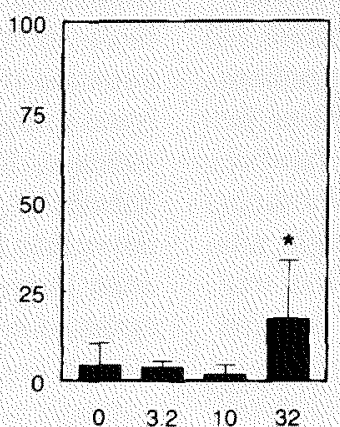

Latency to

Respond (secs)

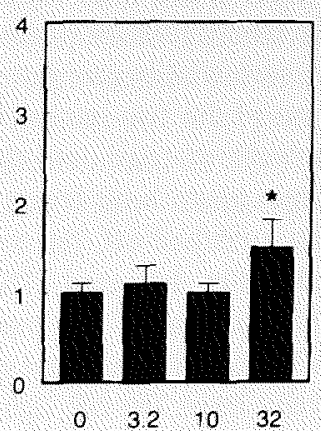

Pirenzepine (Dose $\mu \mathrm{g} / \mathrm{rat}$ )

Percentage

Correct

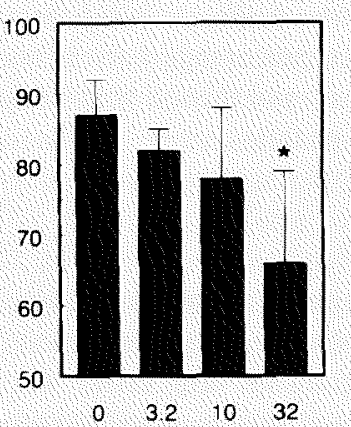

Missed

Trials

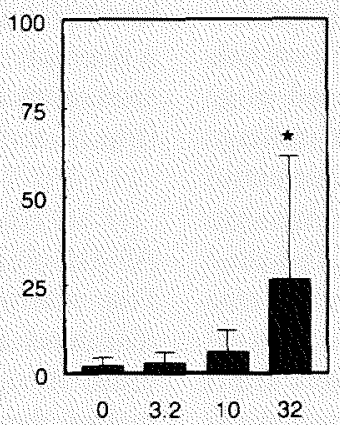

Latency to

Respond (secs)

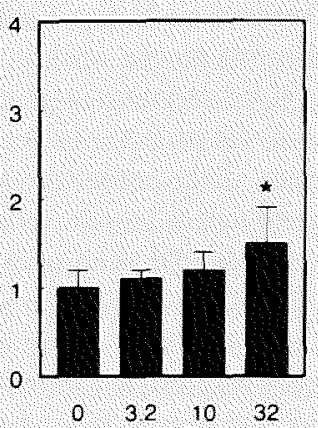

AF-DX 116 (Dose $\mu \mathrm{g} / \mathrm{rat})$

Percentage

Correct

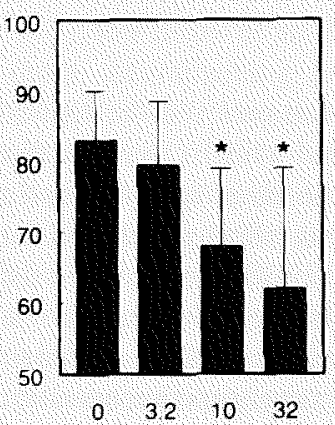

Missed

Trials

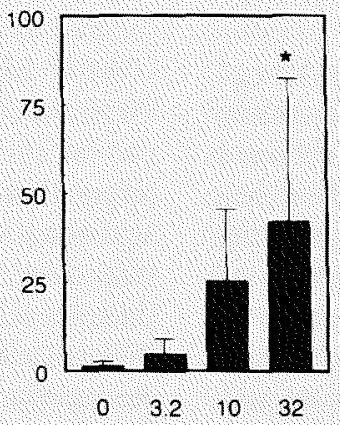

Latency to

Respond (secs)

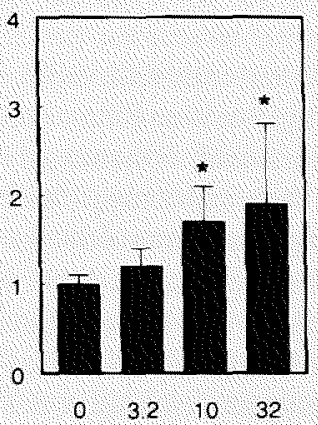

UH-AH 37 (Dose $\mu \mathrm{g} / \mathrm{rat}$ )

FIG. 1 Effects of the $M_{1}$ antagonist pirenzepine, the $M_{2}$ antagonist AF-DX 16 , and the $M_{3}$ antagonist UH-AH 37 on visual discrimination performance in the rat. Doses (n $\mu \mathrm{g}$ per rat $1 . \mathrm{c} . \mathrm{V}$ ) are represented on the horizontal axis. Left panels: effects on accuracy as measured by percentage correct responses, centre panels: mean number of missed trials from a session of 100 trials; right panels: mean latency to respond in seconds. Values are means and standard deviations; " indicates a significant difference from vehicle (0) 


\section{Percentage \\ Correct}

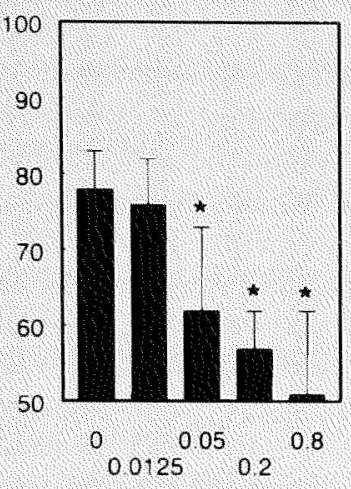

Missed

Trials

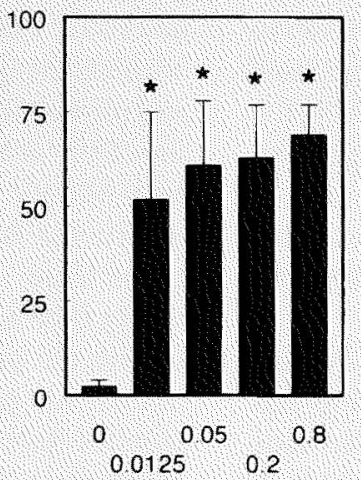

Latency to

Respond (secs)

Scopolamine (Dose $\mathrm{mg} / \mathrm{kg}$ )

\section{Percentage \\ Correct}

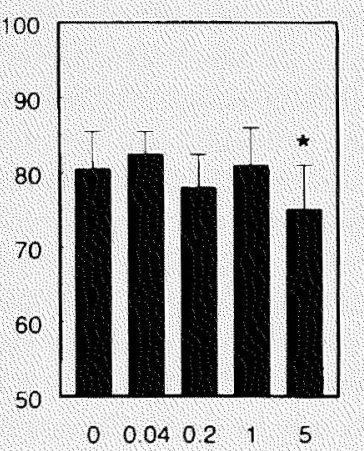

Missed

Trials

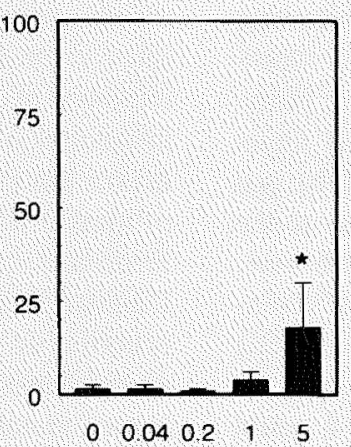

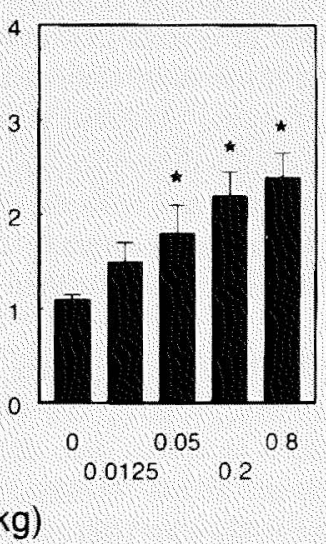

$0.0125 \quad 02$

\section{Latency to \\ Respond (secs)}

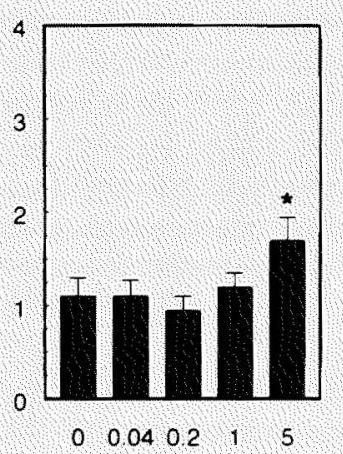

\section{Hemicholinium-3 (Dose $\mu \mathrm{g} / \mathrm{rat}$ )}

FIG 2. Effects of scopolamine and hemicholinium-3 $(\mathrm{HC} 3)$ on visual discrimination performance in the rat. Doses (scopolamine: $\mathrm{mg} / \mathrm{kg} ; \mathrm{HC}_{3}: \mu \mathrm{g} / \mathrm{kg}$ i. C.V.) are represented on the horizontal axis. Left panels: accuracy, as measured by percentage correct responses; centre panels mean number of missed trials from a session of 100 trials, right panels: mean latency to respond in seconds Values are means and standard deviations; " indicates a significant difference from vehicle (0).

latencies $[\mathrm{F}(4,34)=28.9, p<0.01]$ (Fig. 2, upper panel). All but one rat from the $0.05 \mathrm{mg} / \mathrm{kg}$ scopolamine group responded adequately; this rat was removed from the analysis.

\section{Hemicholinium-3}

HC3 decreased correct responding $[F(4,35)=10.9$, $p<0.01]$, and increased failures to respond $[\mathrm{F}(4,35)=15.1, \quad p<0.01]$ and response latencies $[\mathrm{F}(4,35)=25.2, p<0.01]$. Post hoc testing showed that only the highest dose $(5 \mu \mathrm{g})$ had effects on any aspect of performance (Fig. 2, lower panel). All rats responded adequately following HC3 administration.

\section{DISCUSSION}

The highest doses of all compounds enhanced errors of commission (decreased accuracy) and errors of omission (missed trials), as well as increased the latency to respond. In general, the effects of each compound were similar in pattern, although the magnitude differed considerably between compounds. No compound unambiguously disrupted accuracy without affecting latency to respond or trials completed. In the concentrations given, scopolamine and UH-AH 37 induced the most severe effects on all aspects of performance; pirenzepine and $\mathrm{HC} 3$ the weakest.

Several studies have indicated effects of pirenzepine on spatial learning tasks and although effective doses differ between studies, the general pattern of results is similar: 
accuracy is affected before speed or frequency of responding (e.g. Andrews et al., 1994; Bymaster et al., 1993; Hagan et al, 1987). An earlier study had shown that pirenzepine was able to disrupt performance in the DMTP task at a 10-fold lower dose without corresponding effects on ability to respond (Andrews et al., 1994). It should be noted that the effects of pirenzepine in both this and the DMTP study are small and indicate some caution in ascribing a major role for $\mathrm{M}_{1}$ receptors in memory and attention without substantially more data than is available at the current time

The effects of AF-DX 116 were surprising; apart from greater $\mathrm{M}_{2}$ activity in vitro, AF-DX 116 is rather less potent at other muscarinic receptors than the other analogues tested (Doods et al, 1994). To date, $\mathrm{M}_{2}$ antagonists have been reported to have no effect or a facilitating effect on mnemonic performance in rats (Andrews et al., 1994: Doods et al., 1993); there are no comparable studies on visual attention or discrimination. Messer et al. (1990) reported a decrement in performance following intrahippocampal injections of AF-DX 116 in their representational memory task. In the same experiment, pirenzepine was observed to disrupt memory at lower doses and the difference between the effective doses of the two compounds appeared to reflect relative potencies at the $M_{1}$ receptor. A similar explanation is not possible here: the effect of AF-DX 116 was greater than that of pirenzepine, and contrasts strongly with results obtained using similar doses and strain of rats in a DMTP task (Andrews et al, 1994). It seems unlikely that AF-DX 116 could exert a large and selective effect on visual discrimination performance without causing some decrements in complex and demanding procedures such as DMTP. Thus, there is no immediately convincing explanation for these large discrepancies and further research is required to evaluate all the possibilities.

Of the three antagonists tested i.c.V., UH-AH 37 had the most potent effects on performance. The differences between pirenzepine and its close structural analogue UH-AH 37 are potentially the most interesting. Pirenzepine had only a small effect on accuracy at the highest dose, whereas UH-AH 37 had a greater effect on accuracy at both 10 and $32 \mu \mathrm{g}$ doses and suppressed responding more than all other compounds apart from scopolamine

The present data are consistent with a previous study involving DMTP, indicating a more potent disruption of performance by UH-AH 37 than by pirenzepine (Andrews et al., 1994). A number of studies have indicated that in functional assays pirenzepine and UH-AH 37 differ mostly in their effects on $M_{3}$ mediated responses (Hagan et al., 1988; Kilbinger et al,, 1991; Wess et al., 1991; Ten Berge et al, 1993; Doods et al., 1994). Nevertheless, other differences between pirenzepine and UH-
AH 37 in both binding and functional essays, reflecting activity at other muscarinic subtypes, have also been reported (Eberlein et al., 1989; Wess et al, 1991; Bognar et al., 1992, Doods et al., 1994). Therefore, it is debatable whether the difference between the effects of UH-AH 37 and pirenzepine can be solely attributed to the differences in activity at $M_{1}$ and $M_{3}$ receptors. UH-AH 37 also shows high affinity for $M_{4}$ receptors (Doods et al., 1994) and despite the fact that these receptors are much more prevalent in the brain than $M_{3}$ (but not $M_{1}$ ) receptors (Levey, 1993), little is known concerning their pharmacology. To resolve the question as to the relative importance of $\mathrm{M}_{3}$ receptors in performance in the visual discrimination task requires the use of a more selective $M_{1}$ antagonist than pirenzepine and a more selective $\mathrm{M}_{3}$ antagonist than UHAH 37.

The effects of all compounds apart from scopolamine can be assumed to be strictly centrally mediated. Despite the possible involvement of peripheral cholinergic receptor antagonism in the action of scopolamine, the similarities in effects to the other compounds indicate a strong influence of central muscarinic receptors on performance. Dissociating the peripheral and central effects of scopolamine has proven to difficult: qualitatively similar effects of methyl scopolamine and scopolamine on operant performance are often reported: e.g. Andrews et al., 1992; Dunnett et al, 1989; Hudzik and Wenger, 1993 (see Moore et al. (1992) for a discussion). However, the greater suppression of overall responding in the scopolaminetreated animals may be due to the additional antagonism of peripheral cholinergic receptors. Accordingly, it is of interest that scopolamine significantly affected frequency to respond at a lower dose than accuracy, whereas UHAH 37 had a significant effect on accuracy at a lower dose than on trials completed.

Although HC3 has been available for more than 30 years, the number of studies involving complex behaviours remains small. In studies to date the active dose range appears to be $1-5 \mu \mathrm{g}$ per rat i.c.v.; doses higher than this do not have any greater effects on acetylcholine levels in the brain (Freeman et al, 1979). Within this range, effects are seen on acquisition of a lever press (Andrews, unpublished observations), on spatial memory as measured in the swim maze, and in DMTP tasks (Hagan et al., 1989; Andrews et al., 1994), and on aspects of visual attention as measured here and in a serial reaction time task (Muir et al., 1992). Earlier studies using monkeys have suggested a separation of mnemonic and perceptual or motor effects (Ridley et al., 1984, 1987). The effects here and in the earlier DMTP study (Andrews et al., 1994) may indicate that, although the effects on attentional and perceptual factors are close, they are perhaps separable: 1 and $5 \mu \mathrm{g}$ HC3 had similar effects on DMTP, but only $5 \mu \mathrm{g}$ had any effect on the current task. 
Interestingly, a recent study has indicated that attentional tasks involving visual discrimination, such as the fivechoice serial reaction time task, may be less sensitive to HC3 than DMTP (Kirkby et al., 1994). However, other factors such as minor strain differences in the response to HC3 may account for some of the small differences between the studies mentioned above (see also Andrews et al., 1995). The advantages of HC3 over systemically administered antagonists such as scopolamine remain: central activity only; and as the effect is one of cholinergic deficiency and not receptor blockade, receptors can be stimulated directly without first competing with a high affinity antagonist.

To summarise, in agreement with previous studies, these data indicate an important role for the cholinergic system in attentional processes (Dunnett et al, 1991; Rupniak et al, 1991; Muir et al., 1992). It is noteworthy that no compound had an effect on accuracy independent of changes in other aspects of performance. With the exception of AF-DX 116, the relative disruptive effects of the compounds tested were broadly in line with the effects observed in an earlier experiment using a DMTP task (Andrews et al., 1994). The effects of pirenzepine were relatively small and occurred at doses higher than required to disrupt DMTP performance, suggesting some functional selectivity in its cognitive effects. UH-AH 37 induced more potent disruptive effects on visual discrimination performance than pirenzepine, a result consistent with a previous study involving DMTP (Andrews et al. 1994).

\section{Acknowledgements}

The biotechnical assistance of M.T.M. Janssen, J.M.H. Jansen and A. Princen, the biochemical assistance of E. Willems-van Bree, and the software engineering assistance of C.H.W. Neervoort is gratefully acknowledged

\section{REFERENCES}

Andrews IS and Sahgal A (1984) The effects of thyrotropin releasing hormone on a visual discrimination task in rats. Pharmacology Biochemistry and Behavior, 21, 715-719.

Andrews JS and Holtzman SG (1988) Effects of $d$-amphetamine, morphine, naloxone, and drug combinations on visual discrimination in rats. Psychopharmacology, 94, 172-177

Andrews JS, Grützner M and Stephens DN (1992) Effects of cholinergic and non-cholinergic drugs on visual discrimination and delayed visual discrimination performance in rats. Psychopharmacology, 106, 523-530.

Andrews JS, Jansen JHM, Linders S and Princen A (1994) The effects of disrupting the cholinergic system on short-term spatial memory in rats. Psychopharmacology, 115, 489-494.

Andrews JS, Jansen JHM, Linders S, Princen A and Broekkamp CLE (1995) Performance of four different rat strains in the autoshaping, two-object discrimination, and swim maze tests of learning and memory. Physiology and Behavior, 57. $785-790$
Araujo DM, Lapchak PA, Robitaille Y, Gauthier S and Quirion $\mathrm{R}$ (1988) Differential alteration of various cholinergic markers in cortical and subcortical regions of human brain in Alzheimer's disease Journal of Neurochemistry, 50, 1914 1923.

Bognar IT, Altes U, Beinhauer C, Kessler I and Fuder H (1992) A muscarinic receptor different from the $M_{1}, M_{2}, M_{3}$ and $M_{4}$ subtypes mediates the contraction of the rabbit iris sphincter. Naunyn-Schmiedeberg's Archives of Pharmacology, 345. 611-618.

Bymaster FP, Heath I, Hendix JC and Shannon HC (1993) Comparative behavioral and neurochemical activities of cholinergic antagonists in rats. Journal of Pharmacology and Experimental Therapeutics, 267, 1624

Coyle JT, Price DL and Delong MR (1983) Alzheimer's disease: a disorder of cortical cholinergic innervation. Science, 219 , 11841190

Davies P and Maloney AJ (1976) Selective loss of central cholinergic neurons in Alzheimer's disease. Lancet, ii, 1403.

Doods HN, Quirion R, Mihm G, Engel W, Rudolf K, Entzeroth M, Schiavi GB, Ladinsky H, Bechtel WD, Ensinger HA, Mendla KD and Eberlein W (1993) Therapeutic potential of CNS-active $\mathrm{M}_{2}$ antagonists. novel structures and pharmacology. Life Sciences, 52, 497-503.

Doods HN, Entzeroth M, Ziegler H, Mayer N and Holzer P (1994) Pharmacological profile of selective muscarinic receptor antagonists on guinea-pig ileal smooth muscle. European Joumal of Pharmacology, 253, 275-281.

Dunnett SB, Rogers DC and Jones GH (1989) Effects of nucleus basalis magnocellularis lesions in rats on delayed matching and non-matching to position tasks. European Journal of Neuroscience, 1, 395-406.

Dunnett SB, Everitt BJ and Robbins TW (1991) The basal forebrain-cortical cholinergic system: interpreting the functional consequences of excitotoxic lesions. TINS, 14, 494. 501.

Eberlein WG, Engel W, Mihm G, Rudolf K, Wetzel B, Entzeroth M, Mayer N and Doods HN (1989) Structure-activity relationships and pharmacological profile of selective tricyclic antimuscarinics. TIPS, IV 10 (Suppl: Subtypes of Muscarinic Receptors), 50-54.

Evenden J, Marston HM, Jones GH, Giardini V, Lenard L, Everitt BJ and Robbins TW (1989) Effects of excitotoxic lesions of the substantia innominata, ventral and dorsal globus pallidus on visual discrimination acquisition, performance and reversal in the rat. Behavioral Brain Research, 32, $129-149$.

Freeman JJ, Choi RL and Jenden DJ (1975) The effect of hemicholinium on behavior and on brain acetylcholine and choline in the rat. Psychopharmacol Commun, 1, 15-27.

Freeman JJ, Macri JR, Choi RL and Jenden DJ (1979) Studies on the behavioral and biochemical effects of hemicholinium in vivo. Journal of Pharmacology and Experimental Therapeutics, 210, $91-97$.

Hagan JJ and Morris RGM (1988) The cholinergic hypothesis of memory a review of animal experiments. In Handbook of Psychopharmacology. Vol 20 (Eds LL Iversen, SD Iversen and SH Snyder), pp. 237-323. Plenum, New York.

Hagan JJ, Jansen JHM and Broekkamp CLE (1987) Blockade of spatial learning by the $M_{1}$ muscarinic antagonist pirenzepine. Psychopharmacology, 93, 470476.

Hagan JJ, van der Heijden B and Broekkamp CLE (1988) The relative potencies of cholinomimetics and muscarinic antagonists on the rat iris in vivo: effects of $\mathrm{pH}$ on potency of 
pirenzepine and telenzepine Naunyn-Schmiedebergs Archives of Pharmacology, 338, 476483 .

Hagan JJ, Jansen JHM and Broekkamp CLE (1989) Hemicholinum 3 impairs spatial learning and the defict is reversed by cholinomimetics Psychopharmacology, 98, 347-356.

Hudzik TI and Wenger GR (1993) Effects of drugs of abuse and cholinergic agents on delayed matching-to-sample responding in the squirrel monkey. Journal of Pharmacology and Experimental Therapeutics, 265, 120-127.

Hunter AJ and Roberts FF (1988) The effect of pirenzepine on spatial learning in the Morns water maze. Pharmacology Biochemistry and Behavion, 30, 519-523.

Jenden DJ, Macri J, Roch M and Russell RW (1977) Antagonism by deanol of some behavioral effects of hemicholinium. Commun Psychopharmacol, 1, 575-580.

Kilbinger H, Schneider R, Siefken H, Wolf D and D'Agostino G (1991) Characterization of prejunctional muscarnic autoreceptors in the guinea-pig trachea. British Journal of Pharmacology, 103, $1757-1763$.

Kirk RC, White KG and McNaughton N (1988) Low dose scopolamine affects discriminability but not rate of forgetting in delayed conditional discrimination. Psychopharmacology, 96, $541-546$.

Kirkby DL, Jones DNC and Higgins GA (1994) Hemicholinium-3 and cognition, Journal of Pharmacology, Abstract no $52, \mathrm{p} . \mathrm{A} 13$

Kopelman MD (1986) The cholinergic neurotransmitter system in human memory and dementia: a review, Quarterly Joumal of Experimental Psychology, 38a, 535-573.

Ksir C and Slifer B (1982) Drug effects on discrimination performance at two levels of stimulus control, Psychopharmacologia, 43, 3741 .

Levey AI (1993) Immunological localization of $M_{1}-M_{5}$ muscarnic acetylcholine receptors in peripheral tissues and brain. Life Sciences, $\mathbf{5 2}, 441-448$.

Mash DC, Flynn DD and Potter LT (1985) Loss of M, muscarinic receptors in the cerebral cortex in Alzheimer's disease and experimental cholinergic denervation. Science, $\mathbf{2 2 8}$, 1115-1117

Messer WS Jr, Ellerbrock BR, Smith BH and Hoss W (1989) Regional differences in the binding of selective muscarnic antagonists to rat brain: compansons with minimum energy conformations. Journal of Medicinal Chemistr, 32, 1164 1172

Messer WS Jr, Bohnett M and Stibbe J (1990) Evidence for a preferential involvement of $M_{1}$ muscarinic receptors in representational memory. Neuroscience Letters, 116, 184 189

Moore H, Dudchenko P, Comer KS, Bruno JP and Sarter M (1992) Central versus peripheral effects of muscarnic antagonists: the limitations of quatemary ammonium derivatives. Psychopharmacology, 108, $241-243$.
Muir I, Dunnett SB, Robbins TW and Everitt BJ (1992) At tentional functions of the forebrain cholinergic systems: ef fects of intraventricular hemicholinium, physostigmine, basal forebrain lesions and intracortical grafts on a multiple choice serial reaction time task. Experimental Brain Research, 89. 611-622.

Paxinos G and Watson C (1982) The Rat Brain in Stereotaxic Coordinates. Academic Press, Sydney.

Perry EK (1986) The cholinergic hypothesis ten years on British Medical Bulletin, 42, 63 -69

Ridley RM, Barratt NG and Baker HF (1984) Cholinergic learning deficits in the marmoset produced by scopolamine and ICV hemicholinium Psychopharmacology, 83, $340-345$

Ridley RM, Baker HF and Drewett B (1987) Effects of arecoline and pilocarpine on learning ability in marmosets pretreated with hemicholinium-3. Psychopharmacology, 91, 512-514.

Rupniak NMJ, Steventon MJ, Field MJ, Jennings CA and Iversen SD (1990) Comparison of four cholinomimetic agents on cognition in primates following disruption by scopolamine or by lists of objects. Psychopharmacology, 99 189-195.

Rupniak NMJ, Samson NA, Tye SJ, Field MJ and Iversen SD (1991) Evidence against a specific effect of cholinergic dnugs on spatial memory in primates, Behavioral Brain Research. 43, 16 .

Russell RW and Macr J (1978) Some behavioral effects of suppressing choline transport by cerebroventricular injection of hemicholinium-3. Pharmacology Biochemistry and Behavior, 8, 399403 .

Rusted JM, Eaton-Williams P and Warburton DM (1991) A comparison of the effects of scopolamine and diazepam on working memory. Psychopharmacology, 105, 442-445.

Ten Berge REJ, Roffel AF and Zaagsma J (1993) The interaction of selective and non-selective antagonists with pre- and postjunctional muscarnic receptor subtypes in the guinea pig trachea European Journal of Pharmacology, 233, 279-284.

Sala M, Braida D, Calcaterra P, Leone MP, Comotti FA, Gianola $\mathrm{S}$ and Gori E (199) Effect of centrally administered atropine and pirenzepine on radial arm maze performance in the rat. European Journal of Pharmacology, 194, 4549.

Warburton DM and Brown K (1971) Attenuation of stimulus sensitivity induced by scopolamine. Nature, 230, 126 127 .

Wess J, Lambrecht G, Mutschler E, Brann MR and Dorje F (1991) Selectivity profile of the novel muscannic antagonist UH-AH 37 determined by the use of cloned receptors and isolated tissue preparations. British Journal of Pharmacology, 102, $246-250$

(Received 20 December 1994 , accepted as revised
17 May 1995) 